\title{
Properties of Phase Change Energy-storing Inorganic Thermal Insulating Board
}

\author{
Yanjin Wang ${ }^{a}$, Xinfeng Wang ${ }^{b}$ \\ College of Mechanical and Electrical Engineering, Henan Agricultural University, Zhengzhou 450002, \\ China \\ awyanjin2009@163.com, b13643717013@126.com
}

\begin{abstract}
Keywords: Phase change material; Inorganic thermal insulating board; Enclosure structure; Building energy saving
\end{abstract}

\begin{abstract}
Phase change material has broad application prospects owing to its significant advantage of strong heat storage ability in the field of building energy conservation. In the paper, the properties of phase change energy-storing inorganic thermal insulating board were studied. The phase change temperature and latent heat of phase change were analysed by differential scanning calorimetry (DSC). The thermal inertia index of polystyrene board (EPS) and phase change energy storage inorganic insulation board both having the same thickness were calculated and compared. And the experiment in the micro test box was conducted. The research could provide a theoretical basis for the application of phase change energy-storing inorganic thermal insulating board in the building
\end{abstract} field.

\section{Introduction}

Currently, building energy consumption in China accounted for 27.6 percent of the country's total energy consumption and heat loss of enclosure accounted for 70 percent to 80 percent of the total heat loss of the building structure, therefore, strengthening the insulation of the building envelope is a must[1]. The insulation materials are mainly divided into two categories. One is organic insulation materials such as EPS, XPS, PU and so on. According to related document requirements of fire department of the ministry of public security, it is difficult for organic material to achieve the requirement of class A fire protection despite the advantages of low thermal conductivity and good insulation effect. The other is building thermal insulation made of lightweight aggregate, such as expanded perlite and vitrified beads particles. Its advantages are easy to be constructed, firmly bonded with the building envelope, and with class A noncombustible fire resistance capability. The disadvantage is the high thermal conductivity, which can not meet the increasing energy efficiency standards. It is difficult to control the engineering insulation quality, and the use of insulation materials and insulation thickness seriously are affected by the quality of construction workers[2,3].

Phase change material is studied widely and deeply for its high heat storage coefficient, strong thermal storage, high thermal inertia index, ability of resistance temperature wave and heat wave. Currently it has become a widely valued subject to apply the phase change materials in building palisade structure or building regenerator and use the phase change latent heat for energy storage and use in building energy saving field[4,5]. There are many phase change energy storage materials in nature, but few phase transition temperature is fit for the living environment of mankind. Sometimes the phase change materials need to be compounded, and there is no reaction among composite materials, which will result in the loss of phase change function[6,7]. In the paper capric acid and lauric acid were selected as raw materials, with expanded perlite as matrix for composite, and the composite phase-change material was joined in the inorganic insulation board to study its main properties.

\section{Materials and Methods}


In the experiment phase change material was joined in the inorganic insulation board, and the main performance of the phase change energy storage inorganic insulation board was analysed. The main instruments include sartorius electronic balance (Beijing Sartorius Balance Co., Ltd.), differential scanning calorimeter(Model: DSC-200PC, Germany NETZSCHZZ company), paperless temperature recording devices(Model: RX8000, Hangzhou Meacon Automation Technology Co., Ltd.), Pt100 thermocouple(Shanghai Hongrui Precision Iinstruments Co., Ltd.) and so on.

\section{Results and Discussion}

DSC Test of the Phase Change Energy-storing Inorganic Thermal Insulating Board. Phase change energy-storing inorganic insulation board was selected by random sampling, and the phase transition temperature and latent heat of phase change were analysed by differential scanning calorimetry. The test results are shown in Table 1.

Table 1 The DSC test results of phase change energy storage inorganic insulation board

\begin{tabular}{ccc}
\hline Material Name & $\begin{array}{c}\text { Phase Transition } \\
\text { Temperature }\left[{ }^{\circ} \mathrm{C}\right]\end{array}$ & $\begin{array}{c}\text { Phase Transition } \\
\text { Enthalpy[J/g] }\end{array}$ \\
\hline $\begin{array}{c}\text { Phase change } \\
\text { energy-storing inorganic } \\
\text { insulation board }\end{array}$ & 25 & 60 \\
\hline
\end{tabular}

Comparison of Decay Rates and Time Lags of Enclosure Structure. For the building envelope under the large temperature amplitude of the non-steady-state heat transfer condition, only the index of heat transfer coefficient can not fully and accurately evaluate the thermal performance of building envelope. The heat transfer coefficient under the condition of steady-state heat transfer is the main performance parameter describing building envelope heat transfer capability, and is the important technical index for the evaluation of building envelope thermal performance. In the non-steady-state heat transfer condition, in addition to the heat transfer coefficient as a parameter to evaluate the thermal performance of building envelope, the thermal inertia index D which reflects the ability of resistance to the temperature wave and heat wave propagation in the building envelope, should be used.

Comparing EPS board with the phase change energy-storing inorganic insulation board, the thermal insulation layer thickness was changed, and according to the standard of GB50176-93, the thermal inertia index D value, decay rates and time lags of enclosure structure were calculated. The results are shown in Ttable 2.

Table $2 \mathrm{D}, \nu_{o}, \xi$ value of EPS board and phase change energy-storing inorganic insulation board with the same thickness

\begin{tabular}{|c|c|c|c|c|c|c|}
\hline \multirow{2}{*}{$\begin{array}{l}\text { Thickness of } \\
\text { Insulation } \\
\text { Layer } \\
\delta \text { [mm] }\end{array}$} & \multicolumn{3}{|c|}{$\operatorname{EPS}[\rho=30, \lambda=0.042]$} & \multicolumn{3}{|c|}{$\begin{array}{c}\text { Phase Change Energy-storing } \\
\text { Insulation Board } \\
{[\rho=288 \quad \lambda=0.060]}\end{array}$} \\
\hline & D & $\begin{array}{c}\text { Decay } \\
\text { Rates } v_{o}\end{array}$ & $\begin{array}{c}\text { Time } \\
\text { Lags } \\
{[\mathrm{h}]}\end{array}$ & D & $\begin{array}{c}\text { Decay } \\
\text { Rates } v_{o}\end{array}$ & $\begin{array}{c}\text { Time } \\
\text { Lags } \\
{[\mathrm{h}]}\end{array}$ \\
\hline 0 & 2.12 & 5.806 & 4.90 & 2.12 & 5.806 & 4.90 \\
\hline 30 & 2.38 & 40.15 & 5.19 & 3.54 & 45.44 & 10.17 \\
\hline 35 & 2.42 & 45.75 & 5.28 & 3.78 & 83.27 & 11.18 \\
\hline 45 & 2.51 & 57.43 & 5.49 & 4.25 & 156.30 & 13.21 \\
\hline 50 & 2.55 & 63.15 & 5.59 & 4.49 & 215.25 & 14.22 \\
\hline 55 & 2.59 & 68.80 & 5.69 & 4.72 & 296.40 & 15.23 \\
\hline 60 & 2.64 & 74.93 & 5.82 & 4.96 & 4.8.20 & 16.24 \\
\hline
\end{tabular}




$\begin{array}{lllllll}65 & 2.68 & 80.90 & 5.92 & 5.20 & 562.15 & 17.26 \\ 70 & 2.72 & 86.93 & 6.02 & 5.43 & 766.44 & 18.27 \\ 80 & 2.81 & 99.54 & 6.25 & 5.91 & 1453.55 & 20.29\end{array}$

When the outdoor temperature was $35^{\circ} \mathrm{C}$ and the indoor temperature was $25^{\circ} \mathrm{C}$, using $50 \mathrm{~mm}$ EPS board, it cost 5.59 hours for the outdoor temperature affecting the room temperature through the building envelope. Wwhen it came to $50 \mathrm{~mm}$ phase change energy-storing inorganic insulation board, the time was 14.22 hours for the outdoor temperature through the building envelope to affect the room temperature.

Therefore, the phase change energy-storing inorganic insulation board could store thermal effectively, delay affecting on the indoor temperature in the period of 24 hours, maintain the room temperature stable for the $2 / 3$ of the time, and greatly reduce the energy consumption of refrigeration. On the contrary, in the case of the outdoor temperature below room temperature, it could keep the room temperature stable in the $2 / 3$ of the period of 24 hours, greatly reducing the heating energy consumption.

The $\mathrm{K}$ value and $\mathrm{D}$ value of building envelope directly affect cooling and heating load of an air-conditioned room and building energy consumption. With heavy materia, the $\mathrm{D}$ value of envelope structure can reach the requirement, but it is hard to reach the requirement of $\mathrm{K}$ value. The use of lightweight materials can achieve the requirement of the $\mathrm{K}$ value, but to reach the $\mathrm{D}$ value is more difficult. The light weight of the envelope structure is the current development trend, and it is the advantage of phase change materials improving D value of the building envelope.

The Analysis in the Micro Test Box. In order to compare insulation effect of phase change board and EPS board, two micro test boxes were made. Experimental box specification: $30 \times 30 \times 30 \mathrm{~cm}$. For box A the EPS board was used, and for box B the phase change energy-storing inorganic insulation board was used. The test boxes were shown in figure 1 . The left is box A, and the right is box B.

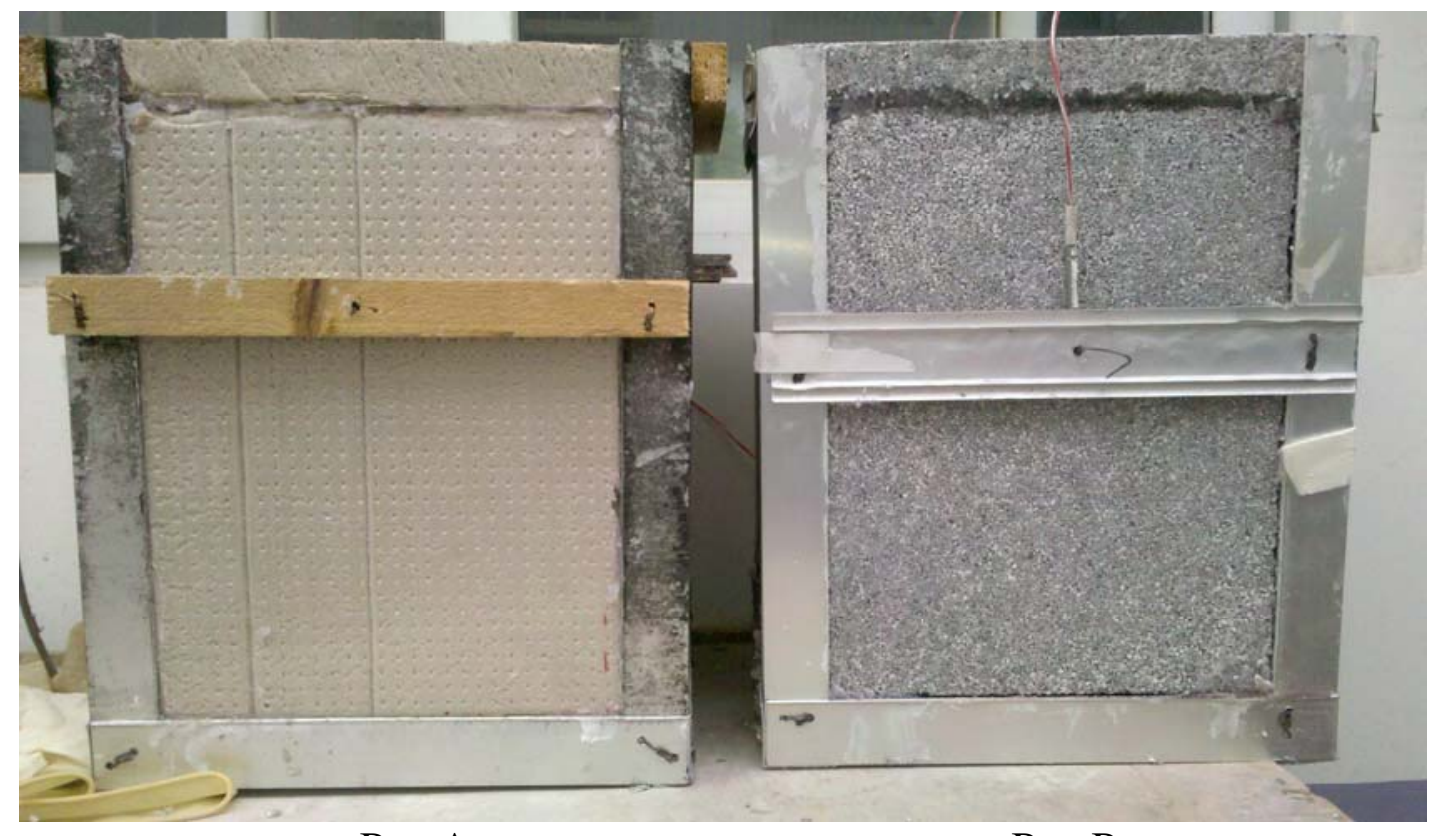

Box A

Box B

Fig. 1 Micro test boxes

In summer, when the ambient temperature was $38^{\circ} \mathrm{C}, \mathrm{A}$ and $\mathrm{B}$ experimental box were put in the sun, Pt100 thermocouples were set inside the box and on the box outer wall, and the temperature changes of the environment, box outer wall and the inside air were recorded by paperless recorder.

When the temperature inside the box both reached $36^{\circ} \mathrm{C}$ for box $\mathrm{A}$ and box $\mathrm{B}$, box A took three hours and twenty-eight minutes, and box B took four hours and fifty-one minutes. The two small 
boxes were put into the freezer at the same time and cooled to $0^{\circ} \mathrm{C}$, and box $\mathrm{A}$ took one hour and twenty-five minutes, box B two hours and nine minutes.

Considering the heating and cooling time, the ability of the phase change board is stronger than that of EPS board to resist temperature changes, and it means that adjusting the temperature through the heat storage and release can resist heat waves better, making the room temperature remain stable for a longer period of time.

\section{Conclusion}

With the further implementation of building energy conservation policy and the gradual improvement of the energy saving index in our country, it is not the best way only by increasing the thermal insulation thickness to improve the insulation effect for the wall insulation. Phase change material has broad application prospects because of its significant advantage of strong heat storage ability, and it can get good application in new construction and existing building energy saving renovation, especially having more space for development in the cold, severe cold area with large temperature difference. The popularization and application of phase change building materials will vigorously promote the development of the industry of exterior insulation.

\section{References}

[1] Zhu Li, Zeping Zhang, and Yuanzhen Liu, et al: submitted to Engineering Mechanics (2006) (in Chinese)

[2] Tianshu Gu, Lianyu Xie, and Ge Chen, et al: submitted to Engineering Mechanics (2006) (in Chinese)

[3] Longtian Wang, Yaoming Yuan: submitted to Construction Conserves Energy (2011) (in Chinese)

[4] Yinping Zhang, Hanping Hu, and Xiangdong Kong, et al: Theory and Application of Energy Storage with Phase Change Materials (Publishing House of the Science and Technology University of China, Hefei 1996)

[5] Hua Zhang, Yugong Xu: submitted to Journal of Hebei Institute of Architectural Science and Technology (2005) (in Chinese)

[6] Kaiming Du, Jiahui Peng, and Mei Li, et al: submitted to Guangzhou Chemical Industry and Technology (2009) (inChinese)

[7] Liang Zhang, Hua Yan, and Rongsheng Yu, et al: submitted to Development and Application of Materials (2010) (inChinese) 